\title{
The public mental health while in a community quarantine due to COVID-19 pandemic: A scoping review of literature using Google Scholar
}

\author{
Ryan V. Labana \\ Department of Biology, College of Science, \\ Polytechnic University of the Philippines, Sta. Mesa, 1008, Manila, Philippines
}

This manuscript was compiled on April 20, 2020

\section{Abstract}

The state of community lock-down due to COVID-19 pandemic caused restricted movements of people. There are existing evidence of the negative impact of quarantine and isolation to the mental health of a person in different contexts. A scoping review of literature using Google Scholar was conducted to discover records about the public mental health while in a community quarantine due to COVID-19 pandemic. A methodological approach suggested by Arksey and O'Malley was utilized. It comprised (a) identifying the research questions, (b) identifying relevant literatures, (c) selecting literature, (d) charting the extracted data, and (e) summarizing, analyzing, and reporting the results. As of April 17,2020 , there were only 4 original articles found that discuss psychosocial aspect of the COVID-19 crisis. After an online survey, they present evidence that (1) there is an outward change in the people's behavior toward selfcare during the pandemic and (2) trusting the community governing bodies can minimize the level of anxiety and stress. Other literatures found are original articles in preprint $(n=8)$, letters, commentaries, editorial $(n=6)$, review paper $(n=4)$, and WHO guideline $(n=1)$. It is evident that the psychosocial aspect of COVID19 crisis needs more attention from the scholars and a large research gap can be lessened trough expansion of online platforms.

Keywords: COVID-19 Pandemic; Review Literature; Psychosocial Support System; Public Health Administration

Send correspondence to: rvlabana@pup.edu.ph

\section{Introduction}

In January 2020, the World Health Organization (WHO) declared COVID-19 as a public health emergency (World Health Organization 2020a). Researchers and scientists from different fields responded to the needs of uncovering various details about the disease including the biology and nature of its etiologic agent, the novel coronavirus or 2019-nCoV (Wang et al. 2020). Clinical experts explained that the development of vaccine against the virus can take several years (World Economic Forum 2020a). Meanwhile social distancing and maintaining proper hygiene through hand washing were advised to the people to lessen the impact of COVID-19 crisis (World Health Organization 2020b). Despite this public health measures, the disease continued to spread across the globe and the number of mortalities continued to increase. Most government in various geographic locations enforced community quarantine and lockdown (The Guardian 2020). It was based on the basic public health measures of quarantine and isolation to avoid the spread of a contagious and a transmissible disease (World Health Organization 2020c).

The state of lock-down restricted the movements of people and it led to halting of usual services in the community (World Economic Forum 2020b). There are existing literatures about the effects of quarantine and isolation to the mental health of a person, so the impact of community lock-down to the mental health of the people confined in their homes due to COVID-19 crisis has also stirred the interests and attentions of the scholars, teachers, students, the government and public health administrators (Brook et al. 2020). Understanding 
this aspect of the COVID-19 crisis is essential in formulating evidence-based interventions and other public health measures.

Due to lockdown of universities and libraries in most communities, searching of information, which is an integral part of research, was limited to using internet at homes. A database like Web of Science typically charge subscription fees for an access to the full text of the research articles themselves and are typically accessible in the university libraries. Google Scholar (GS), a webbased academic search engine, was considered as a powerful tool for finding both specific and a large body of grey literature. It was found to be capable of identifying major evidence with limitations to some vital information needed in a systematic review and meta-analysis (Haddaway et al. 2015). It is a free-to-use academic search engine and can be accessed by most people in their homes, so this is the most accessible search engine in times of community lockdown.

Here, a scoping review of literature was conducted using Google Scholar to help answer the following questions:

1. What are the characteristics of literatures found in Google Scholar that discuss the status of the public mental health while in a community quarantine due to COVID-19 pandemic?

2. What primary data can be accessed in Google Scholar that presents evidence regarding the status of the public mental health while in a community quarantine due to COVID-19 pandemic?

3. What are the research gaps that need to be studied in the future or that need to be searched in major databases?

\section{Methods}

A scoping review was conducted based on the methodological approach suggested by Arksey and O'Malley, which comprised of (a) identifying the research questions, (b) identifying relevant literatures, (c) selecting literature, (d) charting the extracted data, and (e) summarizing, analyzing, and reporting the results (Arksey \& O'Malley 2005).

\section{Identifying relevant literatures}

Literatures for this review were searched on April 13, 2020 from GS. Google Scholar was used because it is the most accessible scientific bibliographic database at home during the state of community lockdown. It has already been used by other scholars in conducting scoping reviews because it contains wide array of records including blogs, thesis, and other grey literature (Prieto-Guttierez 2019). The date range in GS was set to 2019-2020 to delimit the searching within the periods of COVID-19 pandemic. The search terms used were "COVID-19" OR "nCoV" OR "2019-nCoV" OR "2019 novel coronavirus" AND "mental health" OR "psychology" AND "community quarantine" OR "quarantine". All records found were exported to an EndNote Library and then to MS Excel for record management.

\section{Selecting literatures}

All types of literatures were included if they pertain to the public mental health aspect of the COVID-19 pandemic. Since the research questions focus on the mental health of the people confined in their homes during community quarantine, literature related to mental health of the patients in health care facilities and health care providers such as doctors and nurses were not included in the review. Literatures not in English language or with no English translation were excluded. Titles, abstracts, and/or summary were screened by the reviewer against inclusion and exclusion criteria. Further reasons for exclusion were recorded at the full-text stage.

\section{Charting the extracted data}

A data extraction tool was developed by the reviewer which included the type of literature, number of literatures per category, name of the author/s, country where the study was conducted, participants of the study including the sociodemographic profiles, research design, methodology, main findings of the study, and content summary of editorial, commentary, and other non-original articles. 


\section{Summarizing, analyzing, and reporting the results}

Selected literatures were descriptively and numerically summarized. A table was created to reflect the name of the author/s, country where the study was conducted, participants of the study, and research design. A qualitative analysis and reporting of the contents of literatures were conducted per type of literature to answer the research questions.

\section{Results}

\section{Search flow and literature characteristics}

Overall, the search strategy identified 1220 records (Figure). A total of 770 records were found as duplicates, so 450 records were screened with its title and/or abstract. Of 450 records, 291 were related to COVID-19 but did not involve mental health. The topics found included political and economic analysis of the pandemic, patient's care, disease forecasting, incidence reporting, the nature of 2019-NcOV, and others. There were 73 records found about mental health aspect of the topic but were not related to the mental health of the people contained in their homes due to community quarantine. Some examples of the literatures found tackle mental health of patients and/or health care providers, mental health assessment tools and practices, and mental health as a general topic. There were 27 records found not related to COVID-19, 22 records have vague and unstructured titles like "Waiting", "Staying ahead of the Wave", "Most Down Articles", and other titles/headings that do not warrant relevance to the topic being reviewed, and 7 records were not in English language and with no English language translation. Twenty-nine records were eligible for full text assessment but four of them could not be retrieved due to restriction in subscription $(n=1)$ and erratic URL $(n=3)$. A total of 25 literatures
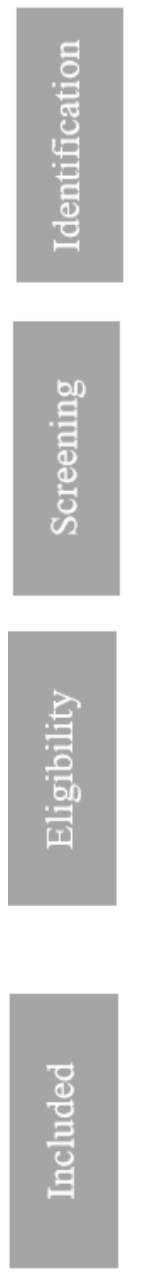

were retained for the final synthesis. The type of literature accessed included original article $(n=4)$ (Lu et al. 2019; Khodabakhshi-koolaee 2020; Wang et al. 2020; Roy et al. 2020), review paper $(n=4)$ (Brook et al. 2020; Sahu et al. 2020; Li et al. 2020; Altena et al. 2020), original article in preprint $(n=8)$ (Hu et al. 2020; Barari et al. 2020; Pancani et al. 2020; Jacobson et al. 2020; Cerami et al. 2020; Cellini et al. 2020; Zhang et al. 2020; \& Pisano et al. 2020). letter/commentary/correspondence $(n=6)$ (Liu et al. 2020; Ho et al. 2020; Whaibeh et al. 2020; Venkatesh et al. 2020; Bao et al. 2020; \& Wang et al. 2020), editorial ( $n=2)$ (Torous et al. 2020 \& Usher et al. 2020), and WHO guideline $(n=1)$ (World Health Organization 2020d).

It can be observed that there is a paucity of
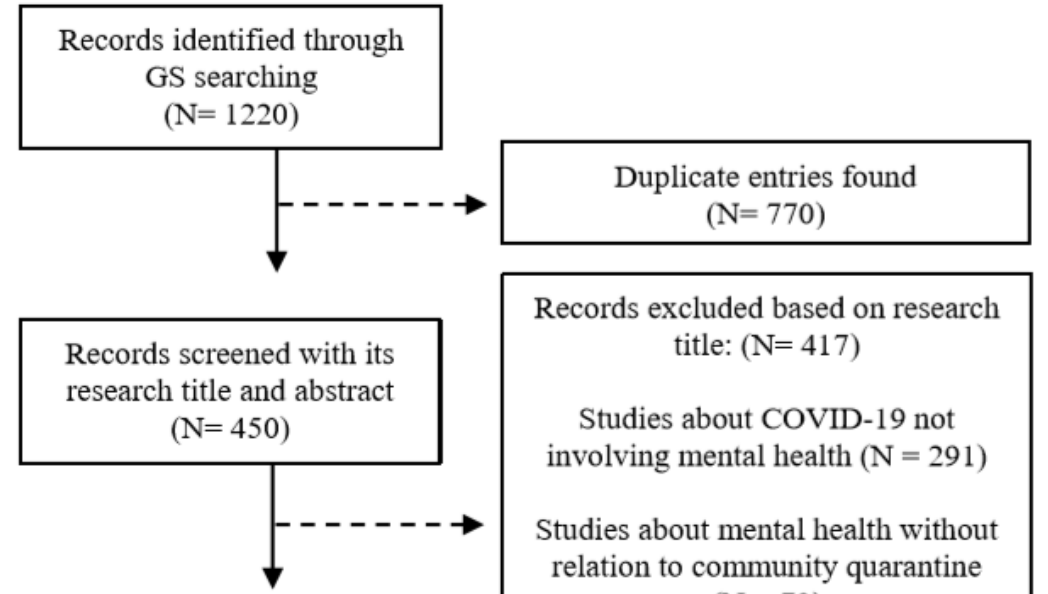

Records excluded based on research title: $(\mathrm{N}=417)$

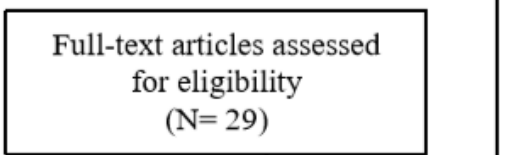

Studies about COVID-19 not involving mental health $(\mathrm{N}=291)$

Studies about mental health without relation to community quarantine $(\mathrm{N}=73)$

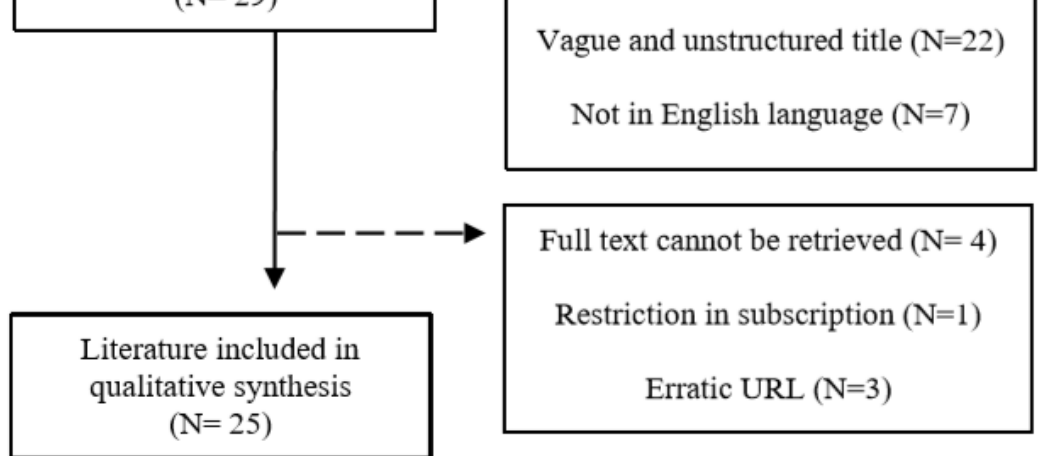

Figure. Flow chart of the literature identification and selection

original articles that can already be used by the public health administrators for an evidencebased decision making. A preprint article is a full draft of paper that is shared to the public prior to editorial and peer review. These articles were 
already assigned Digital Object Identifier (DOI) to reserve credits of its content. They can already be used as references for feedback and discussion, but they do not warrant appropriate quality unless done with the peer review, so medical reports from this paper are not advised to be used in guiding clinical practice (https://www.aje.com/arc/benefits-of-preprintsfor-researchers/).

In the absence of original articles, review paper, commentary/correspondence, editorial, and WHO guidelines can be used in gathering ideas from the experts' point-of-view. These types of articles are product of experts' in-depth analysis of the existing data about the subject matter or other matters related to it. Based on the qualitative analysis of collated records from these types of literature, a theme emerged in this scoping review. The theme was called 'Through the lens of experts: COVID-19, community quarantine, and mental health', and it has three sub-themes including (1) Solidarity of the people in addressing the pandemic lessens fear and anxiety, (2) Social isolation associated with quarantine affects public mental health and (3) Digital health is a promising tool in addressing public mental health crisis.

\section{Through the lens of experts: COVID-19, community quarantine, and mental health Solidarity of the people in addressing the pandemic may lessen fear and anxiety}

In March 2020, the WHO characterized COVID-19 as a pandemic, which means that the risk of spreading the disease across different countries is high (World Health Organization 2020e). As the number of people who have COVID-19 adds up through times, the degree of stress throughout the population also increased. The fear of the people from the possible impact of the pandemic was even exacerbated by the rampant rumors circulating in various media platforms. The health authorities in many geographical locations started managing the misinformation and disinformation about the disease to lessen the peoples' anxiety and distress. Community leaders started encouraging the people to create solidarity in addressing COVID-19 crisis together. Various strategies were formulated by different countries in mitigating mental health burden among the most vulnerable population to enhance mental health support (Ho et al. 2020; Venkatesh et al. 2020; Bao et al. 2020; \& Wang et al. 2020). In Singapore for example, psychological defense is one of the country's five pillars in maintaining faith and trust between the people and the government while going through the crisis (Ho et al.2020). In the Philippines, the Department of Health ensured regular updates about the progress of the outbreak by reaching the people to inform them on the number of recoveries from COVID-19 using their official social media platforms and mainstream media coverage ( $\mathrm{DOH}$ 2020). Many countries strengthened their approaches in addressing paranoia and hysteria by opening the lines of psychiatrists and other mental health care providers to the public (Liu et al. 2020; Ho et al. 2020; Whaibeh et al. 2020; Venkatesh et al. 2020; Bao et al. 2020; \& Wang et al. 2020). These public mental health measures of the government in different countries imply an accord of co-existing challenges between the biological and physical repercussions of the outbreak and the mental health crisis.

\section{Social isolation associated with quarantine affects public mental health}

There are review articles found in Google Scholar that collated evidence on the debilitating impact of social isolation to the person's mental health (Brook et al. 2020). Imposed quarantine requires separation of the person from friends and significant others and avoiding usual everyday routines with other people. In other context, like in the correctional setting or a group of people doing strenuous training activities, this practice is a form of punishment that can cause psychological problems. Some of the identified aspects that trigger this problem include loss of freedom, boredom, physical movement constraints, and other factors that limits individual liberty (Brook et al. 2020, Sahu et al. 2020; Li et al. 2020; Altena et al. 2020).

In the aspect of community quarantine in relation to public health measures against COVID-19, stressors during isolation may include unanticipated duration of quarantine, fears of infections, frustration and boredom, inadequate basic supplies, and inadequate information (Usher 
et al. 2020). Some review papers identify vulnerable groups in the society before, during, and after social isolation. The vulnerable groups include children, females, adolescents, people with pre-existing mental health conditions, and people in poverty (Sahu et al. 2020; Li et al. 2020; Altena et al. 2020).

\section{Digital health is a promising tool in addressing public mental health crisis}

In the time of global health crisis that requires social distancing, public health experts highlighted the important roles of telehealth and digital tools like mobile application (Torous et al. 2020). Digital health or e-health as it is called by others is a technological-driven assistance used by a person in monitoring health and in preventing and treating health problems. It is considered by various health experts as an emerging platform in public health care due to the currently high accessibility of computer, smartphones and tablets and the continuous upgrade of internet connections across the globe. It is a promising tool in dealing mental health problems due to some patients' agoraphobia or fear of social interactions. It offers the patients online self-help, e-therapy, blended care (combination of face-to-face treatment with online sessions), and online information (Ho et al. 2020; Wang et al. 2020). A commentary found in Google Scholar highlighted the promising role of digital mental health to reach the people who are confined in their homes as a measure of flattening the curve of spread of the virus (Whaibeh et al. 2020). Literatures present examples of digital health innovations that can be used in mitigating public mental health problems during the COVID19 pandemic and other global health crises that may arise in the future. Thus, government should invest more on this platform to produce unprecedented results in mental health care (Altena et al. 2020; Ho et al. 2020 \& Whaibeh et al. 2020).

\section{Looking beyond the walls of our homes through internet-based research}

The state of lock-down in most communities controlled the movements of people and it led to stopping of usual services in the community (World Economic Forum 2020b). The state of mental health of the people confined in their homes is an important aspect of the COVID-19 crisis and the availability of information about this topic is of great importance. This information was found scanty in the Google Scholar. The lack of records could be possibly attributed to several factors including the fact that the crisis is still going on, and the research agenda of most experts and scholars focused on other aspects like patients-care, epidemiologic theory or model, vaccine formulation, and other measures concerning the infected individuals. Another factor that hampers the production of enough studies for urgent reporting of research outcomes during the crisis was the restriction of face-to-face interactions between researchers and the community. To address this issue, most investigators of psychosocial aspect of COVID-19 crisis used internet to reach people in their homes and collect data for analysis (Lu et al. 2019; Khodabakhshi-koolaee 2020; Wang et al. 2020; Roy et al. 2020; Hu et al. 2020; Barari et al. 2020; Pancani et al. 2020; Jacobson et al. 2020; Cerami et al. 2020; Cellini et al. 2020; Zhang et al. 2020; \& Pisano et al. 2020).

All identified original articles $(n=4)$ in this scoping review including those that are still undergoing peer review but are already accessible through preprints $(n=8)$ used internet to gather survey responses (Table). Out of 12 studies, a quantitative cross-sectional study design was commonly used $(n=9)$. There were also other study designs used including a quantitative longitudinal survey $(n=1)$, a qualitative with an interpretive phenomenological approach $(n=1)$, and a passive data gathering using "Google Trend" to analyze peoples' disposition based on the mostly searched words in Google $(n=1)$. Some of the weaknesses of this type of data gathering included (a) the difficulty in collecting enough representatives and the lack of quality random sampling that can lead to potential biased analysis, (b) the wastage of data from the incomplete survey questionnaires due to respondents' limited engagement in each survey question, (c) the lack of internet expertise among traditional researchers, and (c) the hurdle of reaching poor communities without a strong internet connection. 
Table: Characteristics of original articles $(n=4)$ and original articles on preprint $(n=8)$

\begin{tabular}{|c|c|c|c|}
\hline Authors & Country & Participants of the study & Research Design \\
\hline Lu et al. (2020) & China & $\begin{array}{l}1849 \text { respondents from mainland China } \\
\text { Females }(65 \%) \text {, Males (35\%); Average } \\
\text { age }=31 \text { years old }\end{array}$ & $\begin{array}{l}\text { Quantitative; Cross-sectional } \\
\text { study using a mobile internet- } \\
\text { based questionnaire }\end{array}$ \\
\hline $\begin{array}{l}\text { Khodabakhshi- } \\
\text { Koolaee (2020) }\end{array}$ & Iran & $\begin{array}{l}15 \text { postgraduate students from Tehran, } \\
\text { Iran }\end{array}$ & $\begin{array}{l}\text { Qualitative with an } \\
\text { interpretive } \\
\text { phenomenological approach } \\
\text { using a semi structure } \\
\text { interviews }\end{array}$ \\
\hline $\begin{array}{l}\text { Wang et al. } \\
(2020)\end{array}$ & China & $\begin{array}{l}\text { First-survey: } 1304 \text { respondents from } 194 \\
\text { cities in China } \\
\text { Second survey: } 861 \text { respondents from } \\
159 \text { cities in China }\end{array}$ & $\begin{array}{l}\text { Quantitative; Longitudinal } \\
\text { study using an online survey } \\
\text { platform }\end{array}$ \\
\hline Roy et al. (2020) & India & $\begin{array}{l}662 \text { respondents from India } \\
\text { Females }(51.2 \%) \text {, Males }(48.6 \%) ; \text { Mean } \\
\text { age }=29.09 \pm 8.83 \text { years old }\end{array}$ & $\begin{array}{l}\text { Quantitative; Cross-sectional } \\
\text { study using an online semi- } \\
\text { structured questionnaire }\end{array}$ \\
\hline Hu et al. (2020) & China & $\begin{array}{l}992 \text { respondents from China } \\
\text { Females ( } 57 \%) \text {, Males ( } 43 \% \text { ); Median age } \\
=36 \text { years old (interquartile range, } 28-42 \text { ) }\end{array}$ & $\begin{array}{l}\text { Quantitative; Cross-sectional } \\
\text { online survey using "Zung- } \\
\text { Self-rating Anxiety Scale" }\end{array}$ \\
\hline $\begin{array}{l}\text { Barari et al. } \\
(2020)\end{array}$ & Italy & $\begin{array}{l}3452 \text { Italian adults } \\
\text { Females ( } 48.5 \%) \text {, Males }(47.9 \%) \text {, Others } \\
(0.4 \%) \text {, Unidentified }(3.1 \%)\end{array}$ & $\begin{array}{l}\text { Quantitative; Cross sectional } \\
\text { survey, perceived by the } \\
\text { reviewer as online survey }\end{array}$ \\
\hline $\begin{array}{l}\text { Pancani et al. } \\
\text { (2020) }\end{array}$ & Italy & $\begin{array}{l}1006 \text { persons in Italy } \\
\text { Females }(80.2 \%) \text {, Males (19.8\%); Mean } \\
\text { age }=29.57 \pm 10.89\end{array}$ & $\begin{array}{l}\text { Quantitative; Cross sectional } \\
\text { online survey }\end{array}$ \\
\hline $\begin{array}{l}\text { Jacobson et al. } \\
(2020)\end{array}$ & $\begin{array}{l}\text { United } \\
\text { States }\end{array}$ & $\begin{array}{l}\text { "An estimated 9,717,876 total searches in } \\
\text { Google" }\end{array}$ & $\begin{array}{l}\text { Analysis using "Google Trend } \\
\text { that normalizes search data } \\
\text { per search locale." }\end{array}$ \\
\hline $\begin{array}{l}\text { Cerami et al. } \\
(2020)\end{array}$ & Italy & 1163 "volunteers" or respondents in Italy & $\begin{array}{l}\text { Quantitative, "baseline } \\
\text { PsyCOVID study using online } \\
\text { survey platform }\end{array}$ \\
\hline $\begin{array}{l}\text { Cellini et al. } \\
(2020)\end{array}$ & Italy & $\begin{array}{l}1310 \text { people living in the Italian territory } \\
\text { Females }(67 \%) \text {, Males (33\%); Mean age } \\
23.91 \pm 3.60\end{array}$ & $\begin{array}{l}\text { Quantitative, Cross-sectional } \\
\text { study using an "anonymous } \\
\text { online survey" }\end{array}$ \\
\hline $\begin{array}{l}\text { Zhang et al. } \\
(2020)\end{array}$ & China & 369 adults in 64 cities in China & $\begin{array}{l}\text { Quantitative, Cross-sectional } \\
\text { survey } \\
\text { using an online platform }\end{array}$ \\
\hline $\begin{array}{l}\text { Pisano et al. } \\
(2020)\end{array}$ & Italy & 5989 children aged 4-10 residing in Italy & $\begin{array}{l}\text { Quantitative, Cross-sectional } \\
\text { survey using an online } \\
\text { platform }\end{array}$ \\
\hline
\end{tabular}

Based on the collated articles in this scoping review, most studies were conducted in the first world countries, which have access to decent internet connection speed and computer hardware. It is a big challenge for the researchers to reach underprivileged people to study the impact of the community quarantine to their mental health in which these groups are expected to be more impacted by the phenomenon. Most of these problems are still hard to fix but to minimize the public potential mistrust from the results of online surveys, researchers were being transparent on the challenges they have encountered during the data gathering. The 
nature and length of questioning and the values and impact of different strategies were also revealed.

\section{The impact of community quarantine to the public mental health due to COVID-19}

As of 17 April 2020, there were only 4 published original articles pertaining to psychosocial crisis during community quarantine due to COVID-19 found in Google Scholar. Of the four original articles, two were conducted in China (Lu et al. 2020 \& Wang et al. 2020), one in Iran (Khodabakhshi-koolaee 2020), and one in India (Roy et al. 2020). Three studies were conducted using a quantitative design while one was conducted using a qualitative with an interpretive phenomenological approach. From these literatures, two themes are apparent: (1) There is an outward change in the people's behavior toward self-care, and (2) Trusting the community governing bodies can minimize stress during the pandemic.

\section{There is an outward change in the people's behavior toward self-care}

Novel coronavirus (2019-nCoV), the etiologic agent of COVID-19, is microscopic but is very contagious. Experts from the $\mathrm{WHO}$ were reiterating the need of ensuring self-protection by keeping proper hygiene and sanitation and maintaining social or physical distancing of at least one meter away from other people (World Health Organization 2020b). Additionally, there were reports of rapid spreading of the disease caused not only by the evidently sick people but also of the asymptomatic individuals (The Guardian 2020). It makes this health crisis literally and figuratively invisible and the state of being unknown increases the peoples' level of anxiety and stress. In a study conducted in Tehran Iran, participants showed apparent change in behavior while living in home quarantine. They have developed obsessive-compulsive behavior toward their body and their washing practices (Khodabakhshi-koolaee 2020). In a study conducted in India among 662 respondents, $84.5 \%$ of them felt the need of constant hand washing and $77.4 \%$ of them perceived the essentiality of hand sanitizers and gloves (Roy et al. 2020). In a study conducted in China, observing better hygiene practices, and avoiding sharing of utensils during meals have significantly lowered the respondents' level of anxiety (Wang et al. 2020).

\section{Trusting the community governing bodies can minimize stress during the pandemic}

In a study conducted in China among 1849 respondents of an online survey, depression among people confined in their houses during community quarantine lessens as they maintain positive attitude toward the pandemic. The positive attitudes were obtained when they received credible real-time updates and when they perceived confidence in pandemic control (Lu et al. 2020). It was supported by another study in China among 1210 respondents during the onset of the health crisis and among 861 respondents during the peak of the health crisis. Investigators related the stable levels of stress, anxiety, and depression among the respondents to the rapid and decisive measures imposed by the Chinese government in controlling the health crisis (Wang et al. 2020). This phenomenon is slightly different from almost half of 662 Indian respondents who expressed being unaffected by the talks of the pandemic on newspaper and news channels, which are presumed to be delivered by the people in the government. Interestingly, more than $80 \%$ of them expressed the need of help from mental health professionals in coping emotional issues during the pandemic as there were increase in levels of anxiety and worries among the public (Roy et al. 2020).

\section{Into the unknown: Understanding research gaps}

There are so many uncertainties in the COVID-19 pandemic, and it causes stress and anxiety in many sectors of the society. The number of studies on the status of the public mental health while in a community quarantine due to COVID19 pandemic were scarce and it should also be given attention by public health administrators the soonest possible time to avoid further complications. Some of the research questions that need to be addressed by scholars include:

- What is the meaning of community quarantine among the impoverished individual?

- What is the quality of food intake of the people confined in their homes and what 
is its impact to the people's brain function and mental health?

- Is resiliency of the poor people helps them in coping the COVID-19 pandemic?

- What are the narratives of social solidarity that can empower the people during the COVID-19 pandemic?

- How does the pandemic amplify the existing problems of the most vulnerable groups of the community including the children, females, and those with preexisting conditions?

- How does the reinforcement of mandatory online classes affect the students' mental health?

- Others

\section{Discussion}

Based on the records found in Google Scholar, it was evident that there is a paucity of studies pertaining to the psychosocial aspect of COVID19 crisis, particularly on the public. The government of various geographic locations tend to focus on viral transmissions and how to interrupt them to avoid further spreading of the disease and cause further hurdles in the health sectors and in the economy. As of April17, 2020, more than half of the COVID-19 records found in Google Scholar talks about biological and physical repercussion of the crisis. When the records that tackle mental health aspect of the pandemic were reviewed, only few literatures were directly related to the experiences of the people confined in their homes. It is understandable that scholars need to focus on people who have COVID-19 but it is also imperative for the governing bodies to pay enough attention to psychosocial aspects of the crisis before it becomes unmanageable. The fear of viral contagion is very high because it is literally and figuratively invisible due to inadequate information about the virus and how to combat them. The same fear should also be felt for the 'invisible' status of the public mental health while in a community quarantine.

This scoping review opens important points for discussion among scholars. First, the use of Google Scholar can be a good practice among researchers during unusual crisis like the COVID19 pandemic. In emergencies like this, grey literature can play an important role in a rapid exchange of ideas toward finding solutions to the emerging problems. Original articles in preprints are not available in the major repositories and it may take some time to finish peer reviews before they can reach major indexing. In this scoping review, more articles about the topic in preprints could be found than the peer-reviewed ones. In a crisis where finding solutions to the problems should be in a fast pace, this type of literature might contain promising answers that are buried from being "grey".

Another point of discussion brought by this scoping review is the importance of editorials, commentaries, and correspondence that promptly fills the gaps of research topic while actual evidence is still unavailable. These types of literatures are usually not included in the systematic reviews but in times of crisis like the COVID-19 pandemic that several hurdles and resolutions are racing against time, they could also be consulted for exploring possible solutions.

Also, the modest primary data found in Google Scholar presents modest answer to the emerging questions. Several research gaps pertaining to psychosocial aspects of COVID-19 crisis were raised in this scoping review. They are either still untapped by the researchers or buried in the major databases that are accessible with subscription. The COVID-19 pandemic brought a lot of uncertainties and the information available in major databases would be more helpful if they are readily available to masses for public consumption.

\section{Conclusion}

Google Scholar is a good web-based academic search engine for finding different types of literature including the original articles in preprints and experts' commentaries. It is a freeto-use academic search engine without subscription fees required, so this is the most accessible search engine in times of community lockdown. Based on this scoping review of literature, the public mental health of the people confined in their homes during quarantine due to COVID-19 is understandably needing more attention. There was an increasing level of anxiety and depression that arise while in quarantine but 
gaining trust of how the government address the crisis significantly reduce the level of negative repercussions. Researchers need to innovate and look for strategies in reaching the people specially those who are most vulnerable in the depressed areas to understand their situation. Online survey is becoming a new normal for scholars, but its weaknesses should be revealed if not resolved. Some research gaps including the quality of food intake of the people while in a community quarantine and its impact to the mental health, the impact of the narratives of solidarity to suppressing people's anxiety, and the impact of online classes to the mental health of the students are important topics for future research.

\section{Compliance with Ethical Standards}

Conflict of interest. The author declares no conflict of interest.

Ethical approval. Ethical approval is not required/not applicable in research based on review of published/publicly reported literature.

\section{References}

AJE Scholars. What are preprints, and how do they benefit authors? [cited 2020 April 13]. Available from https://www.aje.com/arc/benefits-of-preprintsfor-researchers/

Altena, E., Baglioni, C., Espie, C.A., et al. (2020). Dealing with sleep problems during home confinement due to the COVID-19 outbreak: practical recommendations from a task force of the European CBT-I Academy [published online ahead of print, 2020 Apr 4]. J Sleep Res10.1111/jsr.13052. doi:10.1111/jsr.13052

Arksey, H. \& O'Malley, L. (2005) Scoping studies: towards a methodological framework. International Journal of Social Research Methodology: Theory and Practice 8(1):19-

32. DOI: $10.1080 / 1364557032000119616$.

Bao, Y., Sun, Y., Meng, S., Shi, J., Lu, L. (2020). 2019-nCoV epidemic: address mental health care to empower society. Lancet 395 (10224): e37-e38. doi:10.1016/S0140-6736(20)30309-3

Barari, S., Caria, S., Davola, A., Falco, P., Fetzer, T., Fiorin, S., et al. (2020). Evaluating COVID-19 public health messaging in Italy: Self-reported compliance and growing mental health concerns (Preprint) [cited 2020 April 13]. Available from https://www.medrxiv.org/content/10.1101/202 $\underline{0.03 .27 .20042820 v 2 . f u l l . p d f}$

Brooks, S.K., Webster, R.K., Smith, L.E., Woodland, L., Wessely, S., Greenberg, N. et al. (2020) The psychological impact of quarantine and how to reduce it: rapid review of evidence. The Lancet 395 (10227):

P912-920

https://doi.org/10.1016/S0140-

6736(20)30460-8

Cellini, N., Canale, N., Mioni, G., Costa, S. (2020). Changes in sleep pattern, sense of time, and digital media use during COVID-19 lockdown in Italy (Preprint). [cited 2020 April 13]. Available from https://doi.org/10.31234/osf.io/284m

Cerami, C., Santi, G., Galandra, C., Dodich, A., Cappa, S., Vecchi, T., Crespi, C. (2020). COVID19 outbreak in Italy: Are we ready for the psychosocial and economic crisis? Baseline findings from the longitudinal PsyCOVID study (Preprint). [cited 2020 April 13]. Available from https://doi.org/10.31234/osf.io/z7yuv

Cheung, T., Xiang, Y.T. (2020). Progression of Mental Health Services during the COVID-19 Outbreak in China. Int J Biol Sci 16(10):17321738. doi:10.7150/ijbs.45120. Available from http://www.ijbs.com/v16p1732.htm

Department of Health. Updates on novel coronavirus disease (COVID-19) [Cited 2020 April 15]. Available from https://www.doh.gov.ph/2019-nCoV

Haddaway, N.R., Collins, A.M., Coughlin, D., Kirk, S. (2015) The role of Google Scholar in evidence reviews and its applicability to grey literature searching. PLOS ONE 10 (9): e0138237. doi: 10.1371/journal.pone.0138237

Ho, C.S., Chee, C.Y., Ho, R.C. (2020). Mental Health Strategies to Combat the Psychological Impact of COVID-19 Beyond Paranoia and Panic. Ann Acad Med Singapore 49 (3):155160.

Hu, W., Li, S., Quiao, J., Zhu, J., Zhou, Y. (2020). Countrywide quarantine only mildly increased 
anxiety level during COVID-19 outbreak in China (Preprint) [cited 2020 April 13]. Available from

https://www.medrxiv.org/content/10.1101/202 $\underline{0.04 .01 .20041186 v 1}$

Jacobson, N.C., Lekkas, D., Price, G., Heinz, M.V., Song, M., O'Malley, A.J., Barr, P.J. (2020). Flattening the mental health curve: COVID-19 stay-at-home orders result in alterations in mental health search behavior in the United States (Preprint). [cited 2020 April 13]. Available from https://doi.org/10.31234/osf.io/24v5b

Khodabakhshi-koolaee, A. (2020) Living in home quarantine: Analyzing psychological experiences of college students during COVID19 pandemic. Journal of Military Medicine 22 (2): 130-138 doi: 10.30491/JMM.22.2.130

Liu, J.J., Bao, Y., Huang, X., Shi, J., Lu, L. (2020). Mental health considerations for children quarantined because of COVID-19 [published online ahead of print, 2020 Mar 27]. Lancet Child Adolesc Health S2352-4642(20)30096-1. doi:10.1016/S2352-4642(20)30096-1

Lu, H., Nie, P., Quian, L. (2020). Do quarantine experiences and attitudes towards COVID-19 affect the distribution of psychological outcomes in China? A quantile regression analysis GLO Discussion Paper 512. EconStor 2-27 http://hdl.handle.net/10419/215740

Pancani, L., Marinucci, M., Aureli, N., Riva, P. (2020). Forced social isolation and mental health: A study on 1006 Italians under COVID19 quarantine (Preprint). [cited 2020 April 13]. Available https://doi.org/10.31234/osf.io/uacfj

Pisano, L., Galimi, D., Cerniglia, L. (2020). A qualitative report on exploratory data on the possible emotional/behavioral correlates of Covid-19 lockdown in 4-10 years children in Italy (Preprint). [cited 2020 April 13]. Available from https://doi.org/10.31234/osf.io/stwbn

Prieto-Gutierrez, J.J. (2019) Ten years of research on Research Gate: a scoping review using Google Scholar (2008-2017). European Science Editing $45 \quad$ (3): $\quad 60-64$ DOI:10.20316/ESE.2019.45.18023
Roy, D., Tripathy, S., Kar, S.K., Sharma, N., Verma, S.K., Kaushal, V. (2020). Study of knowledge, attitude, anxiety \& perceived mental healthcare need in Indian population during COVID-19 pandemic [published online ahead of print, 2020 Apr 8]. Asian J Psychiatr 51:102083. doi: 10.1016/j.ajp.2020.102083

Sahu, P. (2020). Closure of universities due to coronavirus disease 2019 (COVID-19): Impact on education and mental health of students and academic staff. Cureus 12; (4): e7541. doi:10.7759/cureus.7541

The Guardian. Coronavirus map: which countries have the most cases and deaths [cited 2020 April 13]. Available from https://www.theguardian.com/world/2020/apr/ 21/coronavirus-map-which-countries-have-themost-cases-and-deaths-covid-19

Torous, J., Jän Myrick, K., Rauseo-Ricupero, N., Firth, J. (2020). Digital Mental Health and COVID-19: Using Technology Today to Accelerate the Curve on Access and Quality Tomorrow. JMIR Ment Health 7 (3):e18848. doi:10.2196/18848

Usher, K., Bhullar, N., Jackson, D. (2020). Life in the pandemic: Social isolation and mental health [published online ahead of print, 2020 Apr 6].J Clin Nurs. 10.1111/jocn.15290. doi:10.1111/jocn.15290

Venkatesh, A., Edirappuli, S. (2020). Social distancing in covid-19: what are the mental health implications? BMJ 369: m1379

Wang, C., Pan, R., Wan, X., Tan, Y., Xu, L., et al. (2020) A longitudinal study on the mental health of general population during the COVID-19 epidemic in China [published online ahead of print, 2020 Apr 13]. Brain Behav Immun S0889-1591(20)30511-0. doi: 10.1016/j.bbi.2020.04.028

Wang, G., Zhang, Y., Zhao, J., Zhang, J., Jiang, F. (2020). Mitigate the effects of home confinement on children during the COVID-19 outbreak. Lancet 395(10228):945-947. doi:10.1016/S0140-6736(20)30547-X

Wang, W., Tang, J., Wei, F. (2020). Updated understanding of the outbreak of 2019 novel 
coronavirus (2019-nCoV) in Wuhan, City. J Med Virol 92:441-447 doi/epdf/10.1002/jmv.25689

Whaibeh, E., Mahmoud, H., Naal, H. (2020). Telemental Health in the Context of a Pandemic: the COVID-19 Experience [published online ahead of print, $2020 \mathrm{Apr}$ 2]. Curr Treat Options Psychiatry 1-5. doi:10.1007/s40501-020-00210-2

World Economic Foruma ${ }^{\text {. Why a coronavirus }}$ vaccine takes over a year to produce- and why that is incredibly fast [cited 2020 April 13]. https://www.weforum.org/agenda/2020/04/wh y-a-coronavirus-vaccine-takes-over-a-year-toproduce-and-why-that-is-incredibly-fast/

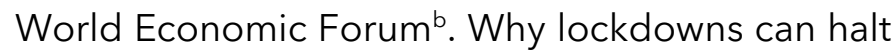
the spread of COVID-19 [cited 2020 April 13]. Available from https://www.weforum.org/agenda/2020/03/wh y-lockdowns-work-epidemics-coronaviruscovid19/

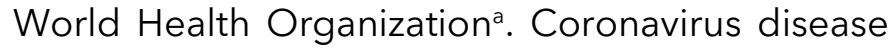
(COVID-19) outbreak [cited 2020 April 13]. Available from: https://www.who.int/westernpacific/emergenci es/covid-19

World Health Organization ${ }^{b}$. Coronavirus disease (COVID-19) advice for the public [cited 2020 April 13]. Available from https://www.who.int/emergencies/diseases/no vel-coronavirus-2019/advice-for-public

World Health Organization'. Chapter 10: Controlling the spread of infectious disease [cited 2020 April 13]. Available from https://www.who.int/healthsystems/topics/heal th-law/chapter10.pdf

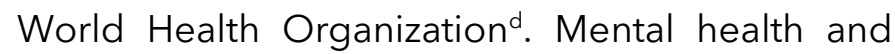
psychosocial considerations during the COVID19 outbreak. [cited 2020 April 13]. Available from

https://apps.who.int/iris/bitstream/handle/106 65/331490/WHO-2019-nCoV-MentalHealth2020.1-eng.pdf

World Health Organizatione. Coronavirus disease 2019 (COVID-19) situation report-51[Cited 2020 April 15]. Available from https://www.who.int/docs/defaultsource/coronaviruse/situation- reports/20200311-sitrep-51-covid19.pdf?sfvrsn=1 ba62e57 10

Zhang, S.X., Wang, Y., Rauch, A., Wei, F. (2020). Unprecedented disruptions of lives and work a survey of the health, distress, and life satisfaction of working adults in China one month into the COVID-19 outbreak (Preprint). [cited 2020 April 13]. Available from https://www.medrxiv.org/content/10.1101/202 $\underline{0.03 .13 .20034496 v 2}$ 